\title{
The Ecological Context of Preschool-Aged Children's Selection of Media Content
}

\author{
Robert David Tom Kalinowski \\ University of California, Irvine \\ Irvine, USA \\ rkalinow@uci.edu
}

\author{
Ying $\mathrm{Xu}$ \\ University of California, Irvine \\ Irvine, USA \\ ying.xu@uci.edu
}

\author{
Katie Salen Tekinbaş \\ University of California, Irvine \\ Irvine, USA \\ ksalen@uci.edu
}

\begin{abstract}
Today, preschool-aged children have an abundance of digital content to choose from, with some more desirable than others from a developmental perspective. We aim to describe and better understand the interplay of factors that influence children's selection of media content using a year-long, multi-case ethnography of 13 diverse families in Southern California. We found that young children's media content selection may be best understood as an ecologically situated process involving the interplay between the content, the child, their family, community, and societal spheres. Children do not make media selections on their own. Rather, these choices are supported or constrained by a range of resource, culture, and policy factors specific to family and community background We argue that policy makers and technology designers are better served by an ecological perspective if they wish to understand how digital content is selected and used by children in sociocultural context.
\end{abstract}

\section{CCS CONCEPTS}

- Social and professional topics $\rightarrow$ Children; - Humancentered computing $\rightarrow$ Empirical studies in $\mathrm{HCI}$.

\section{KEYWORDS}

screen media, children, content selection, ecological perspective

ACM Reference Format:

Robert David Tom Kalinowski, Ying Xu, and Katie Salen Tekinbaş. 2021. The Ecological Context of Preschool-Aged Children's Selection of Media Content. In CHI Conference on Human Factors in Computing Systems (CHI '21), May 8-13, 2021, Yokohama, Japan. ACM, New York, NY, USA, 14 pages. https://doi.org/10.1145/3411764.3445429

\section{INTRODUCTION}

Today, children grow up with internet- connected technologies which did not exist a decade ago $[51,55]$. Smart phones, tablets, voice-activated smart screens, and smart TVs (collectively called "smart screens,") are ubiquitous in US homes and children's age at first use of these technologies is younger with every cohort, with children's first use of mobile touchscreens now below age one [31].

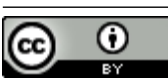

This work is licensed under a Creative Commons Attribution International 4.0 License.

CHI '21, May 8-13, 2021, Yokohama, Japan

(C) 2021 Copyright held by the owner/author(s).

ACM ISBN 978-1-4503-8096-6/21/05.

https://doi.org/10.1145/3411764.3445429
These smart screens are connected to the Internet, enabling children's constant access to the enormous and ever growing amount of media content available online [48], ranging from poorly made, nonsensical YouTube videos featuring unlicensed use of popular characters, to streaming official movie trailers to a big screen TV via an Xbox; from browsing a parent's Pinterest account, to playing a racing game on a cousin's $\mathrm{iPad}$.

Online content is heterogeneous; varying pieces of content posses varying quality, varying functionalities (e.g., whether allowing touchscreen interactivity,) varying purposes (e.g., education or entertainment,) and are created with different ages, genders, cultures, or language speakers in mind [61]. How do children and their families navigate the immense, ever-growing media landscape and make choices about what to consume, whether intentional or unintentional? The issue of content selection is important because different content carries different consequences from a developmental perspective: some content helps the developing child; other content has been found to have no benefit or even deleterious effects [43]. For example, while high-quality content tailored to a child's cognitive level can foster learning (e.g., [28, 65], certain content containing violence can dampen a child's healthy psychological growth (e.g., [67]). During the current coronavirus pandemic, the need to better understand child selection of content has become more urgent, because young children are relying on screen media more heavily to learn or to be engaged such that parents can work from home [22]. Despite an emerging body of literature that focuses on children's screen use in general, little empirical research has been conducted to explore how and why children select certain content and not others within the holistic context of daily life.

The ecological perspective provides theoretical foundations for us to understand the complex processes of children's media content selection (for an overview, see [35]). Ecological systems theory asserts that a child's development can only be understood as situated within multi-level systems including that of the child itself, their family, their community, and larger societal, cultural, and industrial factors with which the child has no direct contact [8]. This notion requires us to simultaneously consider how individual, contextual, and societal forces, as well as the interplay among them, shape children's media selection.

Taking the ecological perspective, we conducted a year-long multi-case ethnography of 13 diverse families with 3- to 4-year-old children that explores (1) how individual children select content on smart screens, (2) how these selections are influenced by the child's family, friends, and immediate community, (3) how these selections are influenced by forces with which the child has no direct interaction, and (4) the features of a complex network of multidirectional influences among different ecological spheres which 
help determine child selection of content. Employing an ethnographic methodology allowed us to situate our investigation within children's daily lives.

We focused on children aged 3 and 4 years because these children are in a stage where selection of digital screen media can be very purposeful, yet children are typically pre-literate and their autonomy for selecting devices or apps out of the universe of choices is still very limited. Growing up with digital technologies is common; research and policy groups have pointed to this age as an important juncture where children must be somehow protected, yet still permitted to grow in digital autonomy. For example, the 5 Rights Foundation calls for "a digital environment that is fit for childhood" and for children's use of digital technologies to always be guided by adults [56]. Thus this age range was likely to produce interesting interplay among ecological systems (e.g., the growing child, the watchful parent, the school community with its screen policies, and the children's media industry) and serve as an interesting test of ecological systems theories. We also focused on children of this age in part because it has been cited as a research priority $[11,41,50]$. Research on daily life with technology among children under 5 is difficult. Common methodologies used in this space such as surveys or interviews will always be somewhat distant from the data generating phenomena, thus much less is known in detail about the use of digital technologies for children under 5 versus other groups.

Because our aim was to more richly describe child selection of content situated in children's social ecologies, it was important for us to draw participants from distinctly different social ecologies, at least at the family and community level within our limited geographical reach. While children were drawn from a number of different communities and cultural backgrounds, we found that all of our participant families could be loosely categorized into two groups: those who are part of Spanish-speaking, working class, immigrant communities and those who are not. While we did not recruit participants intending to divide our sample in two, this division nonetheless emerged. This is important because as we set out to describe the ecologically situated way that children select screen content, we found two sets of rules. The two Americas that emerged in our data and analysis has been described in detail in other contexts by other ethnographers [32-34, 49, 66], and is briefly outlined below. For this study, we assert that drawing from as diverse a pool of families as we could within the scope of the project allowed for more meaningful and trustworthy results.

Overall, we found that far from impressionable people susceptible to any suggestion, children consistently chose screen content for themselves which mirrored their off screen interests; ads or other suggestions for unrelated content were ignored. Rather than being sucked into the screen for time on end, children generally used screen media as a toy, sometimes to be shared, sometimes to be enjoyed in parallel play, and would often choose to lay screen time aside in favor of playing with another person (see [3]). Children almost exclusively selected content designed for children, whether high or low quality. But while we found these strong, universal trends at the individual level, we also found that the world of content from which children could actually choose was dependent on their family structure, their parents attitudes toward screens, and the presence or lack of near-age older siblings. Also, devices and app ecosystems available to young children were entirely dependent on forces outside of the child's direct control. Some families lacked disposable income to spend on child-specific devices; others had strong, anti-screen beliefs and chose to withhold dedicated devices from their children. These family-level choices afforded or constrained whatever young children could choose to consume. We also found important implications for children's media selection made on the community, society, and industrial level. Through all of these interconnected spheres of influence around the individual child, we found two distinct patterns, according to whether or not the child belonged to one of our working class, Spanish-speaking, immigrant neighborhoods. Taken together, our findings shed light on the ecologically-situated nature of children's media content selection, which should be taken in consideration when designing digital content targeting young children.

Our study is distinguished from other studies of children's media usage in the following ways: first, rather than exclusively relying on surveys or laboratory approaches, an ethnographic method enabled us to uncover how children select media over time in natural contexts. We used multiple methods, including multi-case ethnography, semi-structured interviews, surveys, and careful field observations of families and communities which allowed us to make sense of the media selection process by corroborating evidence from multiple sources. Second, while reductive studies have tended to focus on single group of variables that influence what content children consume, our study examined an array of ecologically relevant factors and importantly, the interconnections between them $[18,29,58]$.

\section{RELATED WORK}

\subsection{Examining children's media selection through an ecological framework}

In response to the limitations of narrowly focused digital media effects research which can lack context and lead to poorly informed policy decisions, some media researchers have used qualitative and ethnographic methods to shed light on pressing issues of digital media and children. Livingstone and Sefton-Green, media researchers in the UK, wanted to probe deeply into the meaning-making of digital use in the daily lives of their audience of interest: adolescents. Livingstone and Sefton-Green conducted a year-long ethnography of a single class of 13-14-year-old children at a UK school in their 2016 book, "The Class" [44]. In doing so they were able to probe the dimensions of screen use in adolescents far beyond what survey studies could accomplish. As with the present study, Livingstone and Sefton-Green sought to better characterize media use in sociocultural context, as a way to inform the heated debate at the time of digital technology use in schools for the purpose of formalized education. "The Class" proved to greatly illuminate the debate over tech in schools in Europe, finding, among other things, that much learning with technology occurs out of school in the context of kids wanting to explore and learn in domains that were socially relevant and interesting to them [44]. As "The Class" study was meant to inform the social media harms theories, especially privacy concerns, the authors also found that far from wanting to expose personal information in a myriad of platforms, teens carefully firewalled off identities and information from one platform to another, and avoided some platforms altogether. For instance, teens in the 2016 
study withheld information or participation from Facebook, since that was the same site their parents and teachers used.

A few studies have lent ethnographic methods to preschool technology use. For example, Lorna Arnott used an ecological systems approach to examine preschoolers' use of a wide range of technologies, including digital screens but also non-digital technologies (i.e., electronics or appliances like cassette players and hair irons) in two different preschools in central Scotland [3]. While this study did not have a longitudinal component since individual children's uses of technologies were not tracked over time, Arnott was able to uncover the social nature of play that characterized virtually all use of these tech devices in the participating preschools. Arnott's use of the ecological perspective [9] allowed her to describe a "digital play system" involving different types of social interactions among preschoolers using these technologies [3].

Recent ethnographic work in the area of screen use in ecological context has uncovered important insights, invisible to quantitative methods. Investigators using ethnographic methods resist treating the media using population as monolithic, and instead attempt to prise out a picture of life with technologies for different populations. Some point out that our understanding of important screen use phenomena (like fast internet access, or social media use) is limited to middle or upper class families in the West, and in studying Latino families' we can better understand how technology use and adoption may meaningfully differ for non-white, non-dominant communities [34]. Ethnographic methods have revealed important differences in the ways screen technologies for children are perceived, with Spanish-speaking, immigrant, or low-income families being more opportunity-focused rather than risk-focused $[2,34,66]$. Ethnographic work with parents has also offered keen insight on the effects of risk-focused narratives about screens in the zeitgeist, and the ways this impacts parental mediation of screen use for their kids at home [47].

We applied an ecological perspective to very young children's media use as well as children's language, development, and education across sociological strata more generally. Linebarger and Vaala developed an ecological framework to better understand language development in infants and toddlers as it relates to screen media use. Their framework posited that "a young child's language skills develop from the reciprocal transactions between the child and the broader environmental contexts in which a child is situated or operates" [40]. They concluded that media use impacts language development, and that "the nature and degree of influence is not straightforward," but rather can be better understood by examining a host of important variables and their effects in a multilayered ecological system [40].

With respect to applications of ecological systems theory to broader aspects of child development, we found the ethnography and social history work of Shirley Brice Heath to be important to the present study. While Heath was not focused on media use, her study carefully described the social ecologies of two working class communities, one populated by Whites, another by Black people, and the strikingly different ways language was learned, used, and developed between these two communities and between both of them and the people in the nearby cosmopolitan town [24]. Similarly, we draw from the work of Annette Lareau, who studied the daily lives and trajectories of elementary schoolchildren from different social strata. Lareau's work uncovered two distinct " $t y$ pologies of differences in child rearing": one of "concerted cultivation" and one of "accomplishment of natural growth" [38]. We did not undertake the present study hypothesizing that our participants and the patterns of media selection would fall into bins described by Bryce or Lareau, but as themes began to emerge from the data it became clear that these authors' ethnographies were highly salient to our work. Our research aims to apply ecological frameworks on important aspects of child development to the domain of media selection by young children in the digital age.

\subsection{Socio-technical factors influencing children's media selection}

The socio-technical factors influencing children's media selection have been studied from a range of perspectives. Scholarly work has identified the intermingled algorithmic, commercial, and personal incentives that underlie how media is shown, organized, and selected by users, including children. Walzer has argued that children's media selection is tied, in part, to the algorithmic trust of content creators on YouTube [63]. For example, technological norms, including "reward loops" and "priming" play a key role in shaping children's interaction and are often misaligned with children's developmental needs. Young children, for example, tend to believe what they see and are only beginning to understand that there are social norms and rules to follow, making them particularly vulnerable as users. Moreover, with YouTube, traditional marketing strategies have developed into what some researchers call "persuasive technology," leveraging the interactivity of the technology and matching these with psychological vulnerabilities in specific target demographics [37]. Some observers have argued that children who lack media literacy are more susceptible to the commercialization of YouTube than those who were more familiar with the media world [37].

The work of Livingstone, Kidron, and others point to the need for developmentally appropriate design that supports children in building up individual autonomy as empowered digital citizens. Additional research has focused on ways that caregivers enact methods of meditation affecting how children experience interactive technologies [30, 42, 64]. Mediation styles are closely connected to ongoing narratives around the role of parents and other caregivers in mediating children's relationship with technology "...to mitigate negative effects and provide a scaffold for more mindful use." $[1,57]$ What is lacking in the current research is an understanding of how these various perspectives might operate within an ecological framework. Our research aims to address this gap through a specific focus on media selection.

\section{METHODS}

\subsection{Participants}

We recruited 13 diverse families with at least one child aged 3 or 4 who regularly used digital technologies at the beginning of data collection. We purposefully sought out variation in our sample. Our final participant pool was drawn from a range of communities in Southern California, including a University community, a number of working-class, Spanish-speaking communities, and neighborhoods popular with technology workers and artists within a major 
metropolis. Families spoke primarily English, Spanish, or Chinese in the home. Our 3-4 age range child participants varied in age, gender, developmental characteristics, abilities, interests, schooling contexts, and number and type of digital screens available to them. Children also varied in the number and ages of siblings they had, as well as the number of people total they had living with them. Parents represented a wide range of attitudes on screen and technology use, as well as a range of parenting attitudes regarding screens, from allowing children largely unrestricted use of their own phones, to totally forbidding all screen use at home, (though conceding use at the grandparents' house) (See Table 1).

We used a snowball method to achieve the full participant sample, deliberately seeking out variation in demographic factors and screen use and attitudes. The first author used his personal networks within (1) a University community, (2) a local Head Start organization, and (3) a private school in a nearby metropolis in order to enroll the first participants. Flyers describing the study were distributed among these three networks. Respondents were screened and admitted into the participant pool as appropriate (i.e., according to child ages, child use of screens, accessibility of the homes to researchers, and with an eye toward variation). Respondents also shared news of the study with their own networks, and in this manner participant enrollment was eventually completed. Note that participant families entered the study at different times, but all home visits were completed in a 16-month time frame, from December 2018 to March 2020. All aspects of the study were approved in advance by the authors' home institution IRB.

We took ethical implications of this study very seriously, particularly considering the intimate nature of data collection. Great care was taken to build rapport with all participating families, both those known to the lead researcher beforehand, and those met and befriended on occasion of this study. Participants felt at ease with the researcher(s) present, and also were free to (and liberally did) reschedule visits for any reason. All participants knew that they could terminate their involvement in the study at any time, though we never received any indication that any participant considered doing so. With respect to privacy, our internal review had very carefully considered the nature of the video data and found it to be benign, capturing mundane activity. Furthermore, we did not store information which could be used to connect video data back to individual families. That is, no record of family names, addresses, or signatures exists in our data. Our IRB considered the collection of full names and signatures to add risk, so we never collected or recorded this data.

In table 1 , the more prevalent language used in the home is listed first per family. For the sake of brevity, parental attitudes toward screen use are here generalized into three categories: opportunity focused, risk focused, or balanced, following a Livingston and Blum-Ross categorization of children's media related policy or news organizations [41]. However, the attitudes our participating parents held would more accurately fall on a spectrum, the data and description of which are outside the scope of this paper. We organize Community groups into A: a "University community" bounded by families with at least one parent studying or working at the University and living nearby; B: a "working-class, Spanish-speaking community" including a collection of primarily Spanish-speaking, working-class, immigrant neighborhoods in Southern California, and C: a "tech/artists community" including a collection of neighborhoods within a large metropolis which house and serve media industry professionals.

\subsection{Procedure}

Each family was visited by one or more researchers at home periodically though the data collection phase. The first home visit occurred in December, 2018, and the last in March, 2020. The range of the number of visits per family was 4 for the least-visited to 8 for the most-visited. The average (mean) and most frequented number (mode) of visits per family was 6 . Home visits were scheduled when parents said their child was likely to be using media technology, though other daily-life activities were also observed, including play with traditional toys, family conversation, visits to relatives' homes, and occasional trips out for dining or entertainment. Because researchers visited participants when parents said their children would most likely be using screen media, some families were always visited at the same time of day. This may be considered a limitation, but we note that for many families, this was the only time of day when children were allowed to use screens. In addition to spending time with children, researchers also frequently communicated with parents, near-age siblings, and the occasional family friend/visitor. We employed a method of "participant observation," where the researcher became a participant in the phenomenon of interest, in our case, daily life with screen technologies. Parent report corroborated screen behaviors while a researcher was present to screen behaviours otherwise. The lead author was present for nearly all sessions. There were 78 visits by the end of data collection, all of which were audio and video recorded. In addition, at least one parent in each family participated in a recorded, semi-structured interview. Data sources included audio/video recordings of each visit, field notes, interview transcriptions, researcher reflections immediately following field observations, and photos and notes on families' homes and neighborhoods. At least one parent in each family also took a quantitative survey adapted from the Common Sense census: Media use by kids age zero to eight [55].

\subsection{Analysis}

We used an inductive process to analyse audio/video recordings from family visits. We began with qualitative memoing, a method whereby members of the research team met to systematically review recordings and other data artifacts from home visits. In keeping with with this method, researchers initially viewed some portion of the total body of data recordings together, with each researcher silently memoing their own notes. After specific intervals (usually 5 minutes,) researchers would pause data playback and discuss with one another the meaning that emerged from the data [16, 21]. Through viewing a subset of the video data totaling over 20 hours, we noticed emerging themes related to the ecological situating of child use of media specifically, and selection of content more generally. We then transcribed audio/video data from the majority of family visits (about 45 hours) and began coding child selection of content within ecological systems, developing and revising codes as we found additional examples of child selection within an ecological framework. Transcripts were periodically cross-checked to ensure accuracy. We continued this process using transcripts from visits 
Table 1: Total family members, ages, and community groupings of participant families.

\begin{tabular}{|c|c|c|c|c|c|c|}
\hline Child Name & $\begin{array}{c}\text { Children } \\
\text { Aged } 3 \text { or } 4\end{array}$ & $\begin{array}{l}\text { Sibling } \\
\mathrm{N}\end{array}$ & $\begin{array}{c}\text { Home } \\
\text { Languages }\end{array}$ & $\begin{array}{l}\text { Parental attitudes } \\
\text { toward screens }\end{array}$ & $\begin{array}{c}\text { Devices used } \\
\text { (broad categories) }\end{array}$ & $\begin{array}{l}\text { Community } \\
\text { Group }\end{array}$ \\
\hline Kevin & 1 & 0 & Chinese and English & opportunity & $\begin{array}{l}\text { TV, smartphone, tablet, } \\
\text { game system, home hub }\end{array}$ & $\mathrm{A}$ \\
\hline Addy & 1 & 1 & English & risk & TV, game system & $\mathrm{A}$ \\
\hline Xue & 1 & 1 & Chinese and English & risk & TV, tablet & $\mathrm{A}$ \\
\hline Cleo & 1 & 0 & English & balanced & TV, tablet & A \\
\hline Adam & 1 & 2 & English and Arabic & risk & TV, smartphone & $\mathrm{A}$ \\
\hline Pedro & 1 & 2 & Spanish & opportunity & TV, smartphone, tablet & $\mathrm{B}$ \\
\hline Kristal & 1 & 4 & Spanish and English & opportunity & TV, smartphone & $\mathrm{B}$ \\
\hline Ivy & 1 & 1 & Spanish & balanced & TV, smartphone & $\mathrm{B}$ \\
\hline Imelda & 1 & 2 & Spanish and English & opportunity & TV, smartphone & $\mathrm{B}$ \\
\hline Julia & 1 & 2 & Spanish and English & opportunity & $\begin{array}{l}\text { TV, smartphone, game } \\
\text { system }\end{array}$ & B \\
\hline Eric & 1 & 1 & English & balanced & TV, tablet & $\mathrm{C}$ \\
\hline Xiomara and Wendy & 2 & 2 & English & opportunity & TV, tablets, game system & $\mathrm{C}$ \\
\hline Wilton and Eni & 2 & 0 & English & risk & TV, smartphone & $\mathrm{C}$ \\
\hline
\end{tabular}

with each family, establishing agreement within the research team for examples fitting under themes until no new codes or themes were emerging from the data. [16, 23]. These findings were discussed with colleagues close to the study and with our participants as "member checks"[23]. Findings were again iteratively modified where appropriate.

\section{RESULTS}

In ecological systems theory, the development of the child is understood through the interplay of different ecological levels [8]. Following Bronfenbrenner's work, we organized our results into different ecological spheres: (1) that of the individual child; (2) the microsystem involving the child's immediate family and other direct contacts; (3) the mesosystem, which connects the child's immediate world to larger socio-cultural-industrial systems, and finally (4) the exosystem, which includes governments, policies, and industry players that are beyond the child's immediate reach, but which still impact the child's media selection in powerful, indirect ways. Through each of these ecological levels, we also discuss the content itself, and the multidirectional effects that individual level, content, and ecological systems have on each other.

\subsection{The Individual Child}

Selection of content is not solely a product of outside forces from the individual child. On the contrary, each of our 15 child participants selected content based in part on their own individual characteristics.

4.1.1 Off-screen interests and on-screen selection. Commonly, offscreen interests were reflected in on-screen selections. For example, Pedro is a 3-year-old boy who lives with his parents and two teenage sisters in a mobile home park in a predominantly Spanish-speaking, working-class, immigrant neighborhood. As we drove up to Pedro's house for the first time, we were greeted by enormous tropical plants bursting through large pots along the front wall. Close beside his mother, Pedro rushed up to their large, wooden sliding gate to let us in. As the gate slid aside, we passed into a small courtyard set up like an outdoor room. The concrete ground was covered in most places by a thin mat of plastic grass. And upon the grass were hundreds of toy cars. (We counted at least 200.) There were also two car-themed playmats and a large plastic toy truck which served as both a riding toy and a container for more toy cars. In addition to what we saw before us, I later learned that there were two outdoor storage bins full of toy cars, just for Pedro. Rather than run to his tablet for screen time, Pedro first wanted to show us some of his collection, and immediately started parking cars on one of the parking lot-themed playmats while making excited coos and whispers. (Pedro could not yet talk at the time, and was diagnosed with a speech delay.) His mother knew that we were there to observe his screen time, and gently nudged him to take out the tablet. Eventually, Pedro chose to go inside the mobile home and sit at the small kitchen table. Two researchers gathered near while his mother prepared some fruit. His mother only occasionally glanced at Pedro's screen, and only when she wanted Pedro to show us some specific content, or when Pedro asked her to. Otherwise, Pedro was free to operate the tablet on his own. He knew how to turn on the tablet and access YouTube without help. For the remainder of the visit, Pedro used the YouTube app and almost exclusively selected car videos while keeping scores of toy cars nearby, (see Figure 1). The style and form of these videos was always cheaply generated computer animation. Narration was either absent or very simple. Many videos seemed to have some educational element. For example, one video showed a lineup of computer animated white toy cars sliding down water slides, one by one. As each one reached the bottom, it was dunked into colored liquid, and emerged the same color as the liquid. Once the car emerged, a voice would simply say the name of the color, while the text for that color appeared on screen. In later visits, Pedro would repeat the name of the color aloud, in English. Pedro's mother spoke only Spanish, but Pedro watched a mix of English language and Spanish language videos. 
He made his selection via the toast menu on YouTube while holding the screen in landscape mode, or propping it against the utensil holder on the table.

Perhaps unsurprisingly, Pedro predominantly watched car videos for all our visits over the course of several months. It is noteworthy, however, that at the start of our observations, he never played any app games. After a trip to Mexico to visit his near-age cousins, however, he returned obsessed with one particular driving game. His mother reported that his cousins introduced him to the game and helped him download it, since she herself didn't know how to download apps onto the tablet. Pedro displayed what might be termed an "extremely intense interest" in cars in early childhood [15]. Selecting content which connected to offline interests was a typical behavior we observed in many participants.

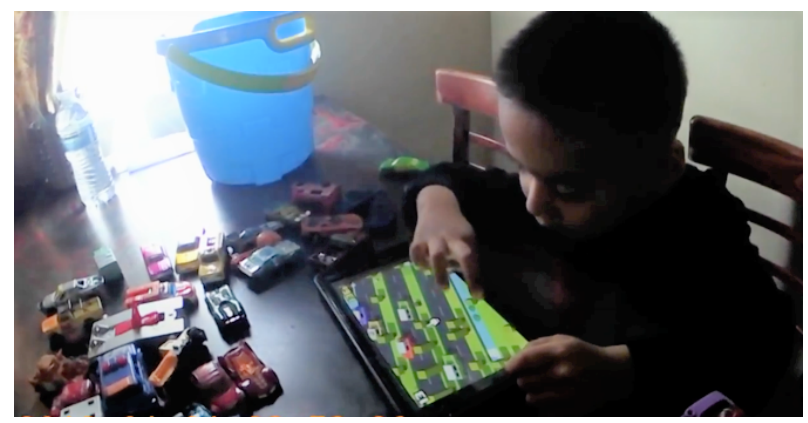

Figure 1: Pedro watching a car-themed video with part of his large collection of car toys in front of him

4.1.2 Tech abilities and tech availability. Abilities in operating digital media technologies varies from child to child, and this variation in ability can also help explain selection.

For example, Addy is a 3-year old girl who lives with her parents and 5-year old brother in a hilly neighborhood adjacent to a major research university. The neighborhood features impeccably clean, broad, winding streets, uniform trees, and uniform houses also. Addy's house is spacious with high ceilings and many rooms on two stories, but doesn't have much of a yard. The floor is covered in plush, new carpet, and the kids kick off their shoes right after entering the house. We always come to visit Addy and her family at the same time of day, because it is the only time of day when the kids are permitted to watch screens. Per their regimented family routine, screen time is after the kids get home from preschool (for Addy) or Kindergarden (for her brother,) and the parents get home from their academic jobs at the university. The parents explain that this is the time the kids can watch screens because they need to work on making dinner. In this case, screens function as a nanny. Addy isn't allowed to watch on a phone or tablet at home, though sometimes her parents allow it while in the car or away from home. For this family, screen time at home is always on the big screen, located across a huge living room from the kitchen while the parents prepare dinner. Screen content selections are always made via via an Xbox. Addy has her own off-screen interests, her own tastes, and her own personality, however, her limited ability to operate the screens available to her dramatically impact her content selection.
She can only make requests of her brother, who exclusively operated the smart TV via the Xbox (see Figure 2). It seemed that Addy was unable or unwilling to do it. During one visit, Addy's brother, Chris, mentioned that he taught her how to operate the screen in the past, but she still prefers that he do it.

Researcher1: So who turned it on? Did you turn it on? Chris: Yeah.

Researcher1: $O k$.

Chris: She doesn't even know how to turn it on.

Addy: Because the tv is ... Chris can control it because mom and dad teach him.

Addy: I have one [viewer profile on Netflix] with Chris, but it doesn't show up so...

Researcher1: Do you want to teach Addy, Chris? Or do you want to..

Chris: Yeah. I already taught her.

Researcher1: oh you already taught her? Ok.

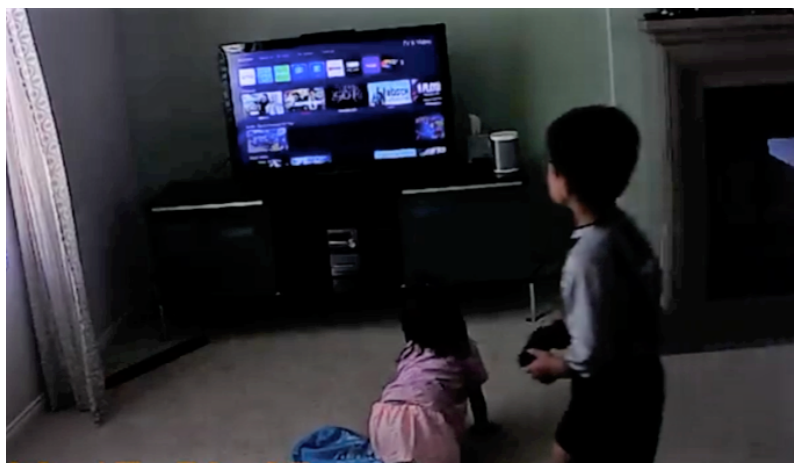

Figure 2: Addy's brother selecting content on the big screen with an Xbox controller while Addy waits

We then proceeded to watch "Captain Underpants" on Netflix, a show that is not designed for 3- or 4-year-olds. Chris, the 5-yearold makes the selection, and Addy defers to his ability in selecting content for the two of them to watch together. Here, we see the interplay between individual characteristics (tech ability,) the child's microsphere (her 5 year old elder brother,) and the exosphere (the industry and society which brings us Netflix via Xbox controlled big screen TVs, along with the many factors which result in the parents decisions on screen policies and screen devices in the home.)

4.1.3 Screens as toys. None of our child participants seemed to prefer screens to the exclusion of all other activities. On the contrary, children frequently looked up from their screens to engage with researchers or family members. Some children took this a step farther, and used screens as a prop or toy during pretend play. In this way, children were able to achieve not co-viewing, but co-play with the screen serving as one of many toys.

For example, Imelda is a 4-year-old girl who lives with her parents, three older sisters, and a visiting aunt in a small apartment in a predominantly Spanish-speaking, working class, immigrant neighborhood. The home is situated at the rear corner of a onestory apartment complex sitting on a standard sized residential plot around the corner from her Head Start site and a local elementary 
school. The streets are wide, straight, and sunny. Giant ficus trees provide shade on very hot summer visits. The concrete pathway leading back to Imelda's apartment is tilted and cracked in places, and the courtyard is more dry sod than grass during the summertime. In the apartment, we enter into a single main room, perhaps 15 feet square, with a double bed, a loveseat, a small kitchen table, a media console with a big screen TV, and many of Imelda's toys strewn about. These toys include a few kid-sized kitchen playsets, plus a fair amount of Barbie dolls and plush toys. All of the toys are scuffed and well worn. One researcher chats with mom at the kitchen table while another starts to video record Imelda. Imelda is delighted to have guests, and immediately engages us in pretend play, asking if we'd like to eat. She sets about making pretend food and serving it on toy plates. Since mom knew we were there to watch Imelda use screens, she tries to get Imelda to sit down and open up her phone. In speaking with Imelda's mother, we find that she's not particularly interested in Imelda's screen use, and views it as just another toy. Indeed, this is how we observed Imelda using screens. On one visit, Imelda used her most frequented device, her mother's phone, to play a Dora the Explorer video on YouTube. Rather than stop her pretend play to watch the video, she instead incorporated it into her pretend kitchen play, propping it up on a toy stove while continuing to play-cook (see Figure 3 ). She generally would not attend to the screen, but occasionally would refer to it, and would move it around her home as she continued in the pretend narrative of cooking for her guests, and hand it to researchers as a topic of conversation. For this particular family, we would make our home visits at different times since Imelda's mother didn't have any specific time established for Imelda's screen use, and since there was no Head Start program over the summer, Imelda, her mother, and sisters enjoyed a lot of free time at home. During every visit, the pattern of use was the same: Imelda preferred social interaction with her guests and pretend play over screens, and the screen would be folded into that type of social play.

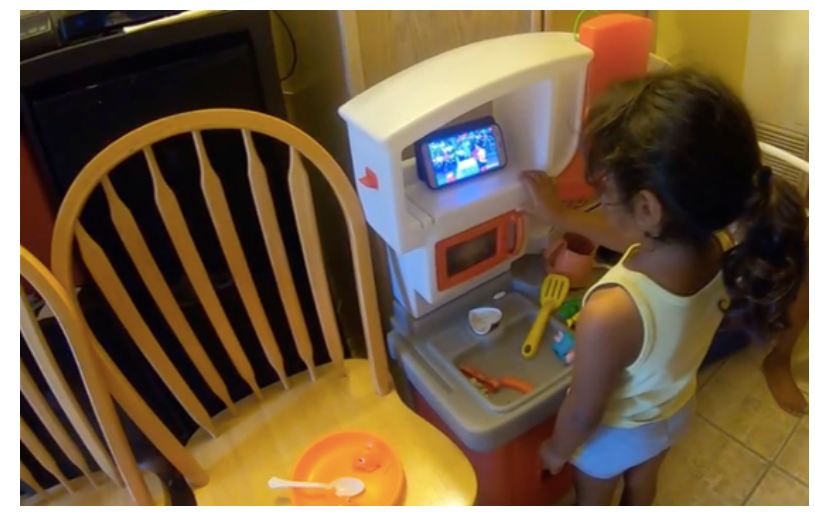

Figure 3: Imelda propping up her mother's smart phone on a toy stove while continuing to play-cook

For Imelda, her personal preference for pretend play determines the way she selects videos as background entertainment. However, there are affordances and limitations of her ecological situation which also determine her content selection. Imelda's family does not have dedicated devices for each child, but Imelda does have plenty of toys and people to play with. Her environment presents her with affordances for certain forms of play, and for her, the limited screens that she can access are only a peripheral piece to that play.

\subsection{The Microsystem: Family Mediation}

In systems theory, the microsystem includes those persons or entities in the child's immediate circle. In our study, we collected rich data on immediate family relationships, as well as some data on schools and peers. We found explicit selection on the part of the parent, as well as parental everyday guidelines, to be powerful forces guiding children's selection of content. Sibling power dynamics also played a role, but only in certain contexts: preschool aged children in our University or Metropolitan communities who had near-age elder siblings would watch together most of the time. However siblings in our Spanish-speaking, working class, immigrant communities did not.

4.2.1 Parent mediation: "concerted cultivation". Parents are situated in their larger socio-cultural spheres. If parents ascribe to a culture which focuses on the risks of screen use for young children, and believe good parenting finds ways to enrich children without screens, then children's selection of content will be impacted.

For example, Wilton and Eni are 4 and 3 year old siblings, living with their parents in an older, more established residential neighborhood in a large metropolitan area. Dad is an architect and mom is an actress and theatre professor. On a Saturday morning, the family, in this case, the nuclear family comprising of dad, mom, and both children, is at home in their classic 1920's house, gathered in a large, sunken living room with huge windows streaming light. The living room is decorated with art on the walls (some of it which the mother made), woven rugs on the floor, and large furniture pieces. In one corner is a child-sized play table covered in Magnatiles and wooden blocks. In front of the sectional couch there is a very small media table holding a 10-year old 23-inch flat screen TV. The younger child, Eni, is selecting content through her parents on the Apple-TV connected television set. Eni voices her desires while a parent operates the remote. Meanwhile, the parents explain some of their perspectives on screen use and parenting to the researchers.

Dad: What do you want to watch? Batman?

Eni: Yeah, Batman!

Dad: This one?

Wilton: Mmm... yeah.

Dad: Okay.

Dad: [to researcher1]But it's also kind of like, um, like you know Wilton with the Tetris, even to some extent, some things on Youtube, some things on the $T V$, and somethings on the phone, it's kind of a way of interacting with the world that is unavoidable. And so I guess we're trying to not be too protective about it, but at the same time responsible. We're not going to just sit here and veg out...

Mom: Yeah, in fact, if this would have been us at home, I would've redirected, and said 'no, let's go do this instead.

Researcher1: Mhm. like she wants to watch batman. 
Researcher1: This is batman? (Referring to a Lego Batman cartoon.)

Eni: Uh huh

Mom: ...Redirect and go outside and play in the garden and then when Dad's not home, like at five o'clock, I start making dinner and if they're not playing well or at all, they'll watch that before dinner.

Wilton and Eni's parents are concerned about screen time risks and try to value other activities in their kids' daily schedule. As a result, the kids do not have their own devices and can only rarely use their parents' phones. Instead, the kids watch on an older model TV, and need to select content through their parents. Content available on the TV screen is limited to only Lego cartoons and PBS Kids at the start of data collection, but later the family bought a subscription to Disney+, and enjoyed watching movies together. The kids do select content, but that content is restricted by forces outside of their control.

For this family, content availability is impacted by different ecological levels, and influence from different levels contributes to further restriction rather than further availability of content. For example, the family used to allow live-action nature shows (e.g., BBC Nature) in addition to Lego cartoons and PBS kids, but Wilton, the 4 year old boy, expressed that the intense action scenes in these shows scared him. Thus, even though Eni, the 3 year old, liked these shows, the parents decided that as a family they wouldn't watch them anymore. For this family, influences from either the individual child level or from the community or cultural level tend to restrict content selection options for the kids.

Throughout data collection, both parents voiced vague anxieties surrounding screen use by their children; (for a study devoted to this topic see [47].) The mother reported a marked improvement in her son's behavior when they became more restrictive with him. (They used to allow him time with their phones in the very early morning, before they were awake.) These parents live in a twostory, architecturally interesting home. They converted a small bedroom into a dedicated playspace for their kids, which includes no digital technologies or screens whatsoever. They also have a yard and a garden, and converted some patio space into a kind of outdoor playhouse. The mother especially takes great care to give the kids highly scaffolded off-screen activities, like specific craft, cooking, and gardening projects. As the father works outside the home and the mother works part-time remotely from home, this is a real strain on parent time and energy, but, following a pattern of parenting behaviors described by Lareau as "concerted cultivation [38]," the parents believe that providing carefully curated off-screen activities targeted to their children is necessary for their healthy growth and development, and they have the resources necessary to follow such a strategy.

4.2.2 Family mediation: "accomplishment of natural growth". Kristal's family's approach to screentime stands in stark contrast to that of Wilton and Eni's family. Kristal is a 3 year old girl who lives in a Spanish-speaking, working class, immigrant community. She lives in a one-room walk up apartment in a small apartment building on a major commercial/residential street. The street has some apartment buildings and some shared homes; just at the corner a Mexican family lovingly tends cages upon cages of parakeets on their front porch. Kristal shares her home with her mother, her father, and her four older siblings. Kristal is 3, while her eldest sister is 18 . Her closest sibling in age is her 8 year old brother Jose. While the family does not have much space, (the one room apartment is dominated by two large bunk beds and a double bed) each of the kids has their own digital devices, except for Kristal, who uses her mom's phone. Kristal always welcomes us with a broad smile, and can't wait to show us her skill and love of screen content. For the most part she would use YouTube, but sometimes she wanted to look at family photos. She always uses her mom's phone to access her content, but sometimes in addition casts the phone screen to a TV via Google Chromecast. Of all our child participants, Kristal is the most adept at using YouTube, despite being one of the younger participants and not yet knowing how to read. Kristal typically navigates by using thumbnails on the toast window in YouTube. She'll tap one thumbnail to get closer to her goal, then quickly scroll through the next set of suggestions and select another thumbnail to get closer and so on. On numerous occasions, she declared to us first what she wanted to watch, and then managed to find the content on YouTube. Even though she is preliterate, she would also occasionally use the search bar and type in gibberish. She would quickly review the search results, and try again if nothing interested her. Eventually, selections that she wanted to watch would appear and she would tap them. We noted that typing gibberish into the search bar would never turn up results representing the full universe of YouTube videos, but rather would always include at least some results related to Kristal's viewing history, evidence that the YouTube search algorithm was at work.

Kristal had a lot of practice with YouTube. Her mother appreciated the affordances of learning from YouTube, and reported that Kristal had learned all her letters, numbers, and colors from "el fone." While her family didn't monitor her viewing behavior closely, there was always a member of the family within arm's reach who could give the minimal amount of help so that Kristal could continue on her way.

Kristal watches YouTube videos on the big screen TV via Chromecast that she selected on her mom's phone. She is standing/sitting near the foot of the bed. Brother is laying on the bed beside her. Mother is sitting on a chair closest to the brother. Other sisters are out on the patio.

Kristal: *scrolling on thumbnails of phone. Looks at the video being shared on the TV above. She puts her hand on her mouth as a reaction to what she is watching. Jose: *Gestures towards her. Kristal: * moves phone away from him. Jose: *Leans in over her shoulder to look at the phone. Kristal: *Looks up to the ceiling (out of frustration because she can't find a particular video.)

Kristal: *Hands phone to mother.

Mom: *Searches through the phone and gives it back to daughter.

Kristal: *Ends up giving mother the phone. Mom: *Taps on search bar and lets the daughter pick 
from the suggested words list.

Mom: *Gives phone back to daughter.

Kristal: *Selects a video and casts it to the TV.

For Kristal, her family members serve as a way to scaffold her own selection of content. In the transcript exerpt above, we see two types of family intervention. First, Kristal's 8-year-old brother Jose briefly monitors what she is watching in response to Kristal's reaction to the content. (Kristal put her hand over her mouth.) Since the content wasn't objectionable, Jose took no further action. Second, Kristal's mother helps Kristal to select her preferred content, and gives Kristal an opportunity to complete the search on her own, before helping a second time. We note the contrasting behaviors effecting Addy's selection of content, described earlier. Addy, a member of the University community with a near-age older sibling, Chris, does not master operation of the devices available to her and will instead defer to her older brother. Factors on multiple ecological levels around Addy serve to constrain her.

In the above exchange we see how multiple members of Kristal's family are nearby to offer support if needed, but for the most part follow a pattern of parenting and family practices in line with Lareau's "accomplishment of natural growth [38]." Lareau described her working class and poor participant families as allowing for more unscaffolded play time. In Lareau's work, working class and poor parents had fewer resources to contribute to paid, organized activities or buying toys or equipment, but had greater resources in terms of relatives always at hand to help keep children safe or help as needed.

\subsection{The Mesosystem: Preschool Policies and Public Interest Groups}

In the ecological model, the mesosystem represents the connections between those groups with which the developing child has direct contact, like family, peers, schools, and local community, and those groups with which they do not, like the US Department of Education or large industries. In the present study, important players in the mesosystem connect parents with the media industry, or connect parents with national policies, like Head Start, WIC, and other social services. According to systems theory, these influences move through the parent to impact the developing child.

4.3.1 Public interest groups and online reviews. In our study, we observed screen-focused public interest groups emerge in this space. The impact of such public interests groups on child selection was demonstrated with Cleo, another resident of the university community. Cleo was three-and-a-half years old when we began our visits, and lives with her mother and father in a large, two-story house in a neighborhood set aside for university professors. She is an only child. Cleo has a charming front yard, with carefully placed broken pottery and native California vegetation thriving in the sun. She runs to the door when we come to visit and seems to love the attention. Cleo watches screens only during a specific scheduled time during the day. After school or summer camp, Cleo arrives home and has an hour of "quiet time" alone in her room without any technology. After this hour, she enjoys her screen time, limited to either watching on a Roku-enabled big screen TV or using a very old iPad with only a few educational apps installed. Cleo responds with excitement every time we arrive for our visits, but her enthusiasm for us as her guests does not prevent her from also wanting to engage in her screen time hour. It seems to us that when we arrive, it is the start of two exciting events in her day: both a visit from her guests and also her screen hour. When she watches the big screen, it is almost always on the Netflix app accessed via Roku, and she requires her mother's help to operate the device and make content selections. Her mother is always present during screen time (the large living room connects directly to the open plan kitchen and dining area) and takes great care with whatever Cleo watches. For a period during our visits, Cleo's favorite show was Netflix' "Chip and Potato," an animated show for kids. As we were all watching together, Cleo's mom explained her process for vetting the show.

Parent: ...there are a bunch of people online on the site who rate these things that disapprove of the show because there are rainbows all over the school. This gives you a sense of [the parenting out there.]

Parent: Oh and it is also a bad show because it encourages lying because [Chip, the main character] always says that the mouse [Potato] is a stuffed animal. She keeps it a secret.

Researcher: So where do you get these online discussions on it?

Parent: So I just saw this on Common Sense Media, which is where I usually go to have an initial check on age level appropriateness.

Researcher: So Common Sense Media said this about this show?

Parent: Not Common Sense Media, but the parent reviews. But the Common Sense Media reviews themselves are fine. They give you a basic sense of what it's about. Um, sometimes the parent reviews are helpful, sometimes they're wackadoodles.

Cleo's mom took great care in reviewing all of the shows Cleo watches though Common Sense Media, a policy group which bridges parents (in children's immediate ecology) and content creators (in the level of the exosphere.) This example also raises another entity that powerfully shapes children's affordances for selection: reviews. While the official Common Sense Media review is positive, there are a few negative reviews from parents on the site which complain about the show promoting lying or homosexuality [4]. While preliterate children have no direct connection to online reviews, these reviews may determine what a child can and cannot access, particularly in screen risk-focused middle-class homes. We note that influence can also move from the child out through to the exosystem, though indirectly, in the form of parent reviews. Our participant parents would sometimes make reviews and recommendations on children's media informed by how their own children respond to the content.

4.3.2 Preschools and screen policies at home. One important social outgrowth of Bronfenbrenner's Ecological Systems Theory was the creation of Head Start. Head Start was designed specifically to address the needs of the developing child on many interconnected societal levels. We found Head Start, other preschool systems, and 
social services to impact children's content selection through leveraging parent opinion and behavior. Several of our participants from our Spanish-speaking, working-class, immigrant communities attended Head Start. One of these Head Start sites propagated a cautious stance on screens to the community as recommended from a larger Head Start program and connections to wider funding sources. In accordance with typical Head Start practices, this view was shared with Head Start families via parent-teacher conversation and parent education nights. This stance reflects not the local community of Head Start families, but the dominant social and professional (risk-focused) voices in the early childhood education space.

The cautious Head Start stance on screen time was not the most cautious in our sample. A Montessori preschool serves members of our participants who live in technology and artist oriented communities in a major metropolitan area. This small, one site, two classroom Montessori preschool had a very strict no screen policy, whereby not only children, but entire families were forbidden from using screens at home. Only one hour of screen time per week was allowed, and that screen time must be a movie and watched together as a family. None of our participants followed the guideline to the letter, but for one family the policy reinforced their own risk-focused policy. This family looked to the school to support their own screen restricting policies at home.

A similar example of mesosystem-level entities impacting selection comes from the Special Supplemental Nutrition Program for Women, Infants, and Children (WIC), a social program in the United States intended to help low income families secure food. Generally, in order to receive WIC benefits, the mother participating in the program must appear in person at a WIC distribution site and prove that certain periodic educational requirements have been met. One of our participants from a Spanish-speaking, working class, immigrant neighborhood regularly received WIC benefits. One of her required educational modules was entirely devoted to teaching WIC recipient mothers that screens are harmful to their children, stating as fact that screens make children hyperactive or cognitively delayed. In this case, a federally funded and managed social service was taking a clear stance on screens, and this messaging can effect screen use by young children in WIC beneficiary families. In our participant family, the WIC module was a topic of conversation at home between the parents: the mother felt more wary of screens, perhaps in part due to the module, whereas the father thought screen use was entirely benign. Perhaps as a result of this WIC educational module and other messaging from the white, middleclass, professional, dominant voices on screen use, the mother in this family felt an ill-defined sense of guilt over screen use for her children, very similar to what Mazmanian and Lanette described for their high-SES, mostly white parent participants [47].

Finally, we also observed YouTube algorithms impacting screen content selection, supporting the work of Walzer referenced above [63]. Kristal, our Spanish-speaking, heavy YouTube user, uses her mom's phone and YouTube account. Thus two people with very different interests share an account. Occasionally, Kristal sees ads that are not targeted to children, like financial services ads. When this happens Kristal sighs, says "oh man!" and will lay the phone flat on the table while dramatically staring at the ceiling. The YouTube algorithm can be thought of as an important entity in the mesosphere, connecting the media company directly to the individual child, though perhaps not with the desired result.

\subsection{The Exosystem: Different Market Segments and Different User Experiences}

The exosystem is inhabited by links between social systems that do not directly involve the child. In our ethnography, we focused our attention directly on the child in order to gain an empathetic understanding of the meaning of screen media to these 3 and 4 year old kids. However, we still should remark here on important players in the exosystem and how we observed their impact on child selection of content.

For child selection of content, the two most relevant entities in the exosphere are industry and mass media. Movements in industry and media do not involve the child, but nonetheless impact the child's ability to select content. For example, dramatic shifts in the media landscape have made touchscreens and video apps ubiquitous today, whereas only a decade ago these were rare. Touchscreens and apps have affordances for child-directed selection of content that prior technologies did not $[10,26]$.

In our study we have seen design decisions on the part of media and technology companies impact child selection, often though a socio-cultural lever whereby certain types of parents purchase and use certain devices and apps. For example, Abby, a 3 year old girl in the University community, selects screen content indirectly via her 5 year old brother, through the Xbox interface of a smart TV. The affordances of the display and controls are quite different from the experience of Kristal, the heavy YouTube user who lives in a Spanish-speaking, working class, immigrant community. One family is attracted to and selects the Xbox and smart TV configuration for a host of sociocultural reasons, including having more disposable income and a certain cultural orientation toward console gaming. Another family has never heard of such a set up and is not interested. As a result, two 3-year old girls will see very different displays and have very different sets of content to choose from when selecting content during their daily, after-preschool screen time.

\subsection{The Macrosystem: attitudes of the culture dictate children's screen environments}

In the ecological framework, the macrosystem is inhabited by the attitudes and ideologies of the culture. Our ethnography uncovered two broad cultures, overlapping in many domains but still distinct. We found these two cultures to be comprised of a dominant voice and a non-dominant voice. The dominant voice is carried by the white, educated, cosmopolitan community, and makes clear proscriptions about kids, screens, and growing up "healthy." This voice is well represented in popular media like national newspapers, best selling books, and daytime talk shows. This voice is also represented in important professional communities, like education and health care communities. Because of its status as the dominant voice, it is represented in big policy decisions, like Head Start screen recommendations and risk-focused educational modules to receive WIC benefits.

There is another voice. The non-dominant voice in our particular sample was that of our Spanish-speaking, working class, immigrant 
communities. This voice is not represented in policy, health, or education decisions, and is seen as pointedly wrong and in need of correction by the dominant voice. That correction takes the form of parent meetings at Head Start sites, well child visits to the pediatrician, and barriers to social services. These two distinct voices align with Heath's cosmopolitan vs. colloquial worlds[24], or with Lareau's descriptions of "concerted cultivation" versus "accomplishment of natural growth" child rearing approaches[38].

In our data, we saw strong echoes of Lareau's work in the form of family dynamics. In one culture, children constantly negotiate. In another, children accept directives from their parents or older relatives. For example, recall Abby from the University community and Kristal from the Spanish-speaking community. In Abby's family, screen time is a tightly controlled commodity, only available during a specific scheduled part of the day, and withheld as punishment. The parents do not watch with their children, but are aware of everything children could be watching, and the universe of video options is tightly constrained. In contrast, Kristal is not restricted in her screen time, and the universe of YouTube on an adult's phone is theoretically accessible. When her mother's phone is available, Kristal can use it. Many older family members are nearby to help if need be, but for the most part Kristal is allowed to explore and develop her skills with her available devices on her own. Abby's mother is focused on risks, and says, "Can you pick one with less shooting?" when Abby goes to select a movie trailer to watch. Kristal's mother is more opportunity focused, and grateful that Kristal has mastered many preschool skills from watching YouTube. Addy is aware of her own capabilities and who to reach out to to help; she's using her family role, and has been cultivated to understand her place in her social structure and how to gain leverage. She negotiates for more screen time almost daily, and we have observed long, quite complex arguments (e.g., "you said yesterday that if I did such-and-such today..") On the other hand Kristal is more capable at using her mother's phone than her mother in some ways. She knows her limitations but seems to understand that she is to expand her capabilities and figure things out for herself. Help is nearby if needed. If mom's phone rings, then Kristal surrenders it without argument.

In this way the macrosystem, via two distinct cultural attitudes, has a powerful effect in shaping children's access to devices and content, and in turn an impact in what content they may select.

\section{DISCUSSION}

The current study may be thought of as an application and test of ecologically situated theories of development in the context of children's selection of media content. Can an ecological systems framework shed light on how and why children select the media that they do? We are unaware of any prior studies which employ multi-case ethnography examining media use in 3- to 4-year-olds' daily lives. Prior studies have included fewer repeated sessions of child observation in natural settings, and little or no direct contact with the full picture of all siblings, parents, preschools, and communities $[11,41,50]$. In our study, we attempted to recruit participants from a purposefully varied range of backgrounds. With this design, it was our hope to be able to capture a more contextualized, interconnected picture of preschool aged children's use of media. With the year-long time span, we also hoped to observe a developmental component of selection through this age range. In this section, we discuss the interpretations of our findings and future directions.

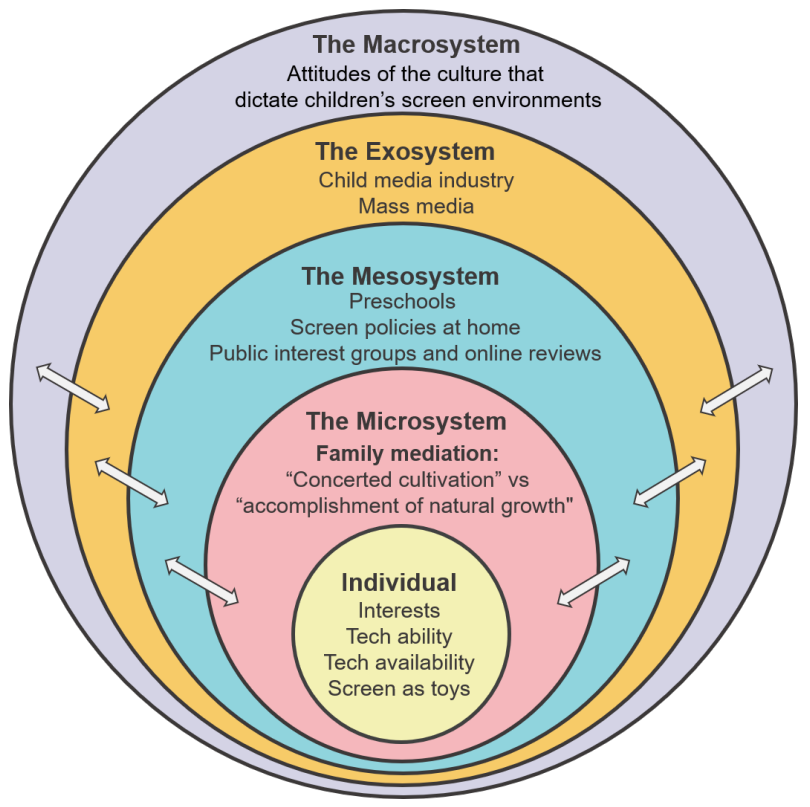

Figure 4: The ecological context of children's selection of media content

\subsection{How do children choose from the wide wide world of content?}

Children do not select content from an infinite world of choice. Our study demonstrated how different levels of the socio-ecological system in which a child is situated greatly restrict or eliminate some choices, while thrusting others forward (see Figure 4). The individual child does have some agency, and children select from their available choices based on their own age, stage, off-screen interests, personalities, and other individual-level factors. However, analogous to robust findings in other social science domains like heritable genetics, we find that much of the vision of limitless choice is an illusion, and factors both directly connected to and disconnected from the developing child constrain choice [60].

We observed Pedro, Addy, and Imelda each select video content via internet-connected screens, but in three very different ways, and showing meaningfully different patterns of use. What can explain how an individual child chooses what to watch? What is the extent of agency on the individual level?

Taking an ecological perspective with our sample, it would seem that no video selection can be fully explained by children's agency. While we clearly see children selecting on-screen content that suits their off-screen interests as with Pedro and cars, the video app and world of content creators also play a role in this selection [63]. Pedro has an interest in cars, just as some children have had early intense interests in cars from before the digital era [15]. The presence of YouTube is perhaps not necessary to fuel this interest in cars. However, YouTube delivers specific content on cars to Pedro, 
contingent on an interplay of algorithmic, commercial, and personal factors. Pedro is not offered the entire universe of car videos; on the contrary, any video we saw him watch about cars could fit into one or two narrow video genres. The algorithm learned what types of car videos Pedro is likely to consume, and content creators, incentivized to work with the algorithm to drive views, are happy to rapidly supply a steady stream of very similar content.

Some scholars have pointed out the "persuasive technology" design elements which keep kids coming back to these apps in specific patterns of use again and again $[10,13]$. We certainly witnessed patterns of use in all 15 of our child participants, and all patterns included repetition of similar or identical content. However, in our data we did not observe children being exploited by manipulative app design. Perhaps part of the reason is that every child in our sample was loved and cared for by dutiful parents. Some parents had a risk-focused view of screens to the extreme, some had an opportunistic view, and most were mixed, but loving parents abided in all homes in the study, and no child was totally unsupported in their tech use. Perhaps another reason is that educational content is so widely available. In Pedro's case, perhaps he could have gotten lost in a morass of disturbing, inappropriate car videos, but child-appropriate, educational car videos are so common, and there was always the presence of a loving adult nearby, if not immediately engaged, to intervene if some unhealthy use pattern were to emerge. In other words, scholars who examine the app platforms and extrapolate dangerous scenarios involving addicted children should contextualize these fears with ecologically valid data: toddlers are not unsupervised on screens indefinitely, and good or benign videos are far more common than unhealthy ones.

Indeed, one important finding from this study is in illuminating the ways parental mediation, along with socio-technical factors of YouTube's operation, operate and interact in an ecological framework. Each of these concepts is itself complex, but they operate together in a further complex ecological system. These case studies throw light on this complex interplay, and allow the reader to evaluate these factors as they work together in real world contexts.

Parents and siblings are closely connected to the individual child, and have a powerful impact in the ways young children select media. We found that patterns of parental and family mediation of screen content can be predicted by membership in one of perhaps two very broad social realms, one of "concerted cultivation" and another of "accomplishment of natural growth," following Annette Lareau [38].

Forces both directly involving and disconnected from children pull children's selection choices in different directions. One vector is in the same direction that the child would want to go according to their individual characteristics. Children recruit family members to support their interests; YouTube algorithms suggest similar content, etc. Another vector is to pull children in new or different directions, like the culturally dominant voice as represented by preschool teachers, pulling children toward more educational content and more interactive content, and less passive or purely entertainment content. Preschools tell parents to allow for less entertainmentbased screen time; more interactive, educational content is made available by parents' purchasing of dedicated devices or apps, etc.

At the very center of this complex model of child selection of content is the child. Children are not passive consumers; the child has their own voice, their own spirit, their own way in the world. In the present study we've seen at least one way that this voice can travel up through the layers of the ecological model to inform the creation of media itself: parents publish content reviews based in part on their children's response to that content. These reviews, in turn, may inform content programming decisions from content creators and broadcasters like Netflix or PBSKids. Another mechanism by which the individual child's voice may inform media creators at the exosystem level is via user testing. Technology and media companies regularly carry out user testing with children as part of the design process to make their products responsive to their target markets. Following the ecological perspective, individual children respond to the content available to them as consumers, but they also play a role in influencing content production and the designs of the devices on which that content is consumed [17].

\subsection{Policy and Design Implications}

These findings have shed light on how we may scaffold children's choosing of educational, developmentally appropriate media, leveraging ecological contexts.

An ecological view can serve to enhance the design process for children's media and technology. In the current prevailing design paradigm, child-centered design, designers recognize the critical role of children and place them at the center of the design process. This paradigm would be improved by taking a broader view and considering other factors surrounding the child. For example, parents are key stakeholders who engage in children's technology use at home, but they are not often seen as active design partners when developing child-centered technologies. An exception would be a recent study where Vezzoli used cultural probes and contextual interviews to explore unique design spaces for parent-child shared reading as a quality family time [62]. Similarly, design research could probe into the ecological spaces connected to the target child and their parent, such as systematically considering siblings and preschools as important predictors of specific dimensions of child use.

Second, some research has been conducted to develop recommendation algorithms in the hope of providing children with personalized support in decision making about content [14]. However, these algorithms are usually based solely on children's historic usage and fail to consider the broader socio-cultural contexts a child is situated in, thus leading to biased results that may simply reinforce children's poor selection habits. Such algorithms could go beyond the individual child and consider family, community, and cultural contexts by gathering contextual data from parents or teachers. This may increase the likelihood of curating appropriate content for children, thus enhancing children's media experiences.

\subsection{Limitations and Future Work}

Findings from this study suggest at two broad sociological groups which are differentially impacted with respect to children's selection of content by the social-ecological systems that they are part of. We do not mean to suggest, however, that our Spanish-speaking, working class, immigrant community is representative of such communities throughout the United States or even California, nor do 
we mean to conflate our community with those that prior ethnographers have studied. Immigrant people to the United States from Latin America have important differences from working class or poor groups of White or Black Americans, participant populations of sociologists like Heath [24] or Lareau [38]. Further, the locality of this study, Southern California, has special considerations that when coupled with the Spanish-speaking immigrant demographic cannot be conflated with other low-income groups [32-34, 49]. However, we maintain that even with these well studied differences between our working class community and other communities in similar socio-economic standing, we saw a strong pattern emerge of two different groups in our participant population. This work is meant to be richly descriptive to provide insight on the phenomena of young children selecting their own digital media content in a variety of families and communities. It is not meant to be representative.

Future steps for this research project are to investigate how screen content selection has changed among these groups and others given the pandemic shutdown of public life and resulting increase in screen use for education, entertainment, and keeping kids occupied while parents work from home.

\section{CONCLUSION}

While preschool-aged children conceivably face an enormous amount of choice during screen time, little is known about the factors that shape or constrain those choices for individual children. Our paper depicts an ecology of children's media content selection, which involves the interplay between the content, the child, their family, community, and societal spheres. While devices are indeed in children's hands and children make selections mostly through their own finger tips, these choices are supported or constrained by a range of resource, culture, and policy factors specific to family and community background. As such, we propose that policy makers and technology designers are better served by an ecological perspective if they wish to understand how digital content is selected and used by children in sociocultural context.

\section{ACKNOWLEDGMENTS}

The authors acknowledge the work of research assistants Branda Tian Sun, Tran Bao Hoang, Leslie Gissel Rosales, Elizabeth ValenciaCastillo, Dorthy Schmidt, and Rosemary Velasquez, without whom this study would not be possible. We also thank Professor Mark Warschauer, who advised and enthusiastically supported this research project.

\section{REFERENCES}

[1] Christie Anne Abel and Thomas D Grace. 2020. Designing dyadic caregiver-child personas for interactive digital media use. In Proceedings of the Interaction Design and Children Conference. 198-204.

[2] Morgan G Ames, Janet Go, Joseph'Jofish' Kaye, and Mirjana Spasojevic. 2011. Understanding technology choices and values through social class. In Proceedings of the ACM 2011 conference on Computer supported cooperative work. 55-64.

[3] Lorna Arnott. 2016. An ecological exploration of young children's digital play: framing children's social experiences with technologies in early childhood. Early Years 36, 3 (2016), 271-288.

[4] Emily Ashby. 2019. Chip and Potato - TV Review. https://www. commonsensemedia.org/tv-reviews/chip-and-potato

[5] Nellie Bowles. [n.d.]. A dark consensus about screens and kids begins to emerge in silicon valley. The New York Times ([n.d.]). https://www.nytimes.com/2018/ 10/26/style/phon Retrieved from.
[6] Nellie Bowles. [n.d.]. The digital gap between rich and poor kids is not what we expected. The New York Times ([n.d.]). https://www.nytimes.com/2018/10/26/ style/digit Retrieved from.

[7] Nellie Bowles. [n.d.]. Silicon valley nannies are phone police for kids. The New York Times ([n.d.]). https://www.nytimes.com/2018/10/26/style/silico Retrieved from.

[8] Urie Bronfenbrenner. 1979. The ecology of human development. Harvard university press.

[9] Urie Bronfenbrenner. 1994. Ecological models of human development. Readings on the development of children 2, 1 (1994), 37-43.

[10] Benjamin Burroughs. 2017. YouTube kids: The app economy and mobile parenting. Social media+ society 3, 2 (2017), 2056305117707189.

[11] Stéphane Chaudron, ME Beutel, Veronica Donoso Navarrete, M Dreier, Ben Fletcher-Watson, AS Heikkilä, V Kontríková, RV Korkeamäki, S Livingstone, J Marsh, et al. 2015. Young Children (0-8) and digital technology: A qualitative exploratory study across seven countries. JRC; ISPRA, Italy.

[12] J. Daniel. [n.d.]. Our letter to the APA. Children's Screen Time Action Network. https://screentimenetwork.org/apa Retrieved from.

[13] Jessica Daniel. 2018. Our letter to the APA. https://screentimenetwork.org/apa

[14] Yashar Deldjoo, Cristina Frà, Massimo Valla, Antonio Paladini, Davide Anghileri, Mustafa Anil Tuncil, Franca Garzotta, Paolo Cremonesi, et al. 2017. Enhancing children's experience with recommendation systems. In Workshop on Children and Recommender Systems (KidRec'17)-11th ACM Conference of Recommender Systems. N-A.

[15] Judy S DeLoache, Gabrielle Simcock, and Suzanne Macari. 2007. Planes, trains, automobiles-and tea sets: Extremely intense interests in very young children. Developmental psychology 43, 6 (2007), 1579.

[16] Sharon J Derry, Roy D Pea, Brigid Barron, Randi A Engle, Frederick Erickson, Ricki Goldman, Rogers Hall, Timothy Koschmann, Jay L Lemke, Miriam Gamoran Sherin, et al. 2010. Conducting video research in the learning sciences: Guidance on selection, analysis, technology, and ethics. The journal of the learning sciences 19, 1 (2010), 3-53.

[17] Rebecca A Dore, Marcia Shirilla, Brian N Verdine, Laura Zimmermann, Roberta Michnick Golinkoff, and Kathy Hirsh-Pasek. 2018. Developer meets developmentalist: improving industry-research partnerships in children's educational technology. Fournal of Children and Media 12, 2 (2018), 227-235.

[18] Susan Edwards. 2013. Digital play in the early years: A contextual response to the problem of integrating technologies and play-based pedagogies in the early childhood curriculum. European early childhood education research journal 21, 2 (2013), 199-212.

[19] Nelly Elias and Idit Sulkin. 2017. YouTube viewers in diapers: An exploration of factors associated with amount of toddlers' online viewing. Cyberpsychology: Journal of Psychosocial Research on Cyberspace 11, 3 (2017).

[20] J. Eng. [n.d.]. Child advocacy groups say youtube kids rife with 'inappropriate'

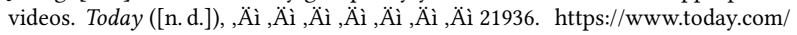
money/child-advocacy- Retrieved from.

[21] Randi A Engle, Faith R Conant, and James G Greeno. 2007. Progressive refinement of hypotheses in video-supported research. Video research in the learning sciences (2007), 239-254.

[22] Caroline Gaudreau, Yemimah A King, Rebecca A Dore, Hannah Puttre, Deborah Nichols, Kathy Hirsh-Pasek, and Roberta Michnick Golinkoff. 2020. Preschoolers Benefit Equally From Video Chat, Pseudo-Contingent Video, and Live Book Reading: Implications for Storytime During the Coronavirus Pandemic and Beyond. Frontiers in Psychology 11 (2020), 2158.

[23] Egon G Guba, Yvonna S Lincoln, et al. 1994. Competing paradigms in qualitative research. Handbook of qualitative research 2, 163-194 (1994), 105.

[24] Shirley B Heath and Shirley Brice Heath. 1983. Ways with words: Language, life and work in communities and classrooms. cambridge university Press.

[25] Tiffany Rose Hildre. 2019. Institutionalised tension in public service media between children as digital citizens and as digital consumers: A case study of the development of NRK Super's Fantorangen app. Master's thesis.

[26] Donell J Holloway, Lelia Green, and Kylie J Stevenson. 2015. Digitods: Toddlers, touch screens and Australian family life. (2015).

[27] Juan Pablo Hourcade, Sarah L Mascher, David Wu, and Luiza Pantoja. 2015. Look, my baby is using an iPad! An analysis of YouTube videos of infants and toddlers using tablets. In Proceedings of the 33rd Annual ACM Conference on Human Factors in Computing Systems. 1915-1924.

[28] Brittany Huber, Joanne Tarasuik, Mariana N Antoniou, Chelsee Garrett, Steven J Bowe, Jordy Kaufman, and Swinburne Babylab Team. 2016. Young children's transfer of learning from a touchscreen device. Computers in Human Behavior 56 (2016), 56-64.

[29] Mizuko Ito, Kris Gutiérrez, Sonia Livingstone, Bill Penuel, Jean Rhodes, Katie Salen, Juliet Schor, Julian Sefton-Green, and S Craig Watkins. 2013. Connected learning: An agenda for research and design. Digital Media and Learning Research Hub.

[30] Hee Jhee Jiow, Sun Sun Lim, and Julian Lin. 2017. Level up! Refreshing parental mediation theory for our digital media landscape. Communication Theory 27, 3 (2017), 309-328. 
[31] Hilda K Kabali, Matilde M Irigoyen, Rosemary Nunez-Davis, Jennifer G Budacki, Sweta H Mohanty, Kristin P Leister, and Robert L Bonner. 2015. Exposure and use of mobile media devices by young children. Pediatrics 136, 6 (2015), 1044-1050.

[32] Vikki S Katz. 2010. How children use media to connect their families to the community: The case of Latinos in Los Angeles. Fournal of Children and Media 4, 3 (2010), 298-315.

[33] Vikki S Katz. 2014. Kids in the middle: How children of immigrants negotiate community interactions for their families. Rutgers University Press.

[34] Vikki S Katz and Carmen Gonzalez. 2016. Community variations in low-income Latino families' technology adoption and integration. American Behavioral Scientist 60, 1 (2016), 59-80.

[35] Silvia H Koller, Marcela Raffaelli, and Normanda Araujo de Morais. 2020. From Theory to Methodology: Using Ecological Engagement to Study Development in Context. Child Development Perspectives (2020).

[36] Katarzyna Kostyrka-Allchorne, Nicholas R Cooper, and Andrew Simpson. 2017. The relationship between television exposure and children's cognition and behaviour: A systematic review. Developmental Review 44 (2017), 19-58.

[37] A. Lafrance. [n.d.]. The algorithm that makes preschoolers obsessed with YouTube kids. The Atlantic ([n. d.]). https://www.theatlantic.com/technology/archive/2 Retrieved from.

[38] Annette Lareau. 2011. Unequal childhoods: Class, race, and family life. Univ of California Press.

[39] YS Lincoln and EA Guba. 1985. rvaturalistic inqttiry. Beverly Hills.

[40] Deborah L Linebarger and Sarah E Vaala. 2010. Screen media and language development in infants and toddlers: An ecological perspective. Developmental Review 30, 2 (2010), 176-202.

[41] Sonia Livingstone and Alicia Blum-Ross. 2017. Researching children and childhood in the digital age. In Research with Children. Routledge, 66-82.

[42] Sonia Livingstone and Alicia Blum-Ross. 2019. Parents' Role in Supporting, Brokering or Impeding Their Children's Connected Learning and Media Literacy. Cultural Science fournal 11, 1 (2019).

[43] Sonia Livingstone and Leslie Haddon. 2009. Kids online: Opportunities and risks for children. Policy press.

[44] Sonia Livingstone and Julian Sefton-Green. 2016. The class.

[45] Sonia Livingstone, Mariya Stoilova, and Rishita Nandagiri. 2019. Children's data and privacy online: growing up in a digital age: an evidence review. (2019).

[46] Marie-Louise Mares and Zhongdang Pan. 2013. Effects of Sesame Street: A metaanalysis of children's learning in 15 countries. Journal of Applied Developmental Psychology 34, 3 (2013), 140-151.

[47] Melissa Mazmanian and Simone Lanette. 2017. " Okay, One More Episode" An Ethnography of Parenting in the Digital Age. In Proceedings of the 2017 ACM Conference on Computer Supported Cooperative Work and Social Computing. 22732286.

[48] Emily McReynolds, Sarah Hubbard, Timothy Lau, Aditya Saraf, Maya Cakmak, and Franziska Roesner. 2017. Toys that listen: A study of parents, children, and internet-connected toys. In Proceedings of the 2017 CHI Conference on Human Factors in Computing Systems. 5197-5207.

[49] Wendy Ochoa, Stephanie M Reich, and George Farkas. 2020. The observed quality of caregiver-child interactions with and without a mobile screen device. Academic
Pediatrics (2020).

[50] Office of Communications. 2017. Children and parents: Media use and attitudes report 2017. (2017)

[51] Amy Orben and Andrew K Przybylski. 2019. The association between adolescent well-being and digital technology use. Nature Human Behaviour 3, 2 (2019), $173-182$.

[52] George C Patton and Susan M Sawyer. 2000. Media and young minds. The Medical journal of Australia 173, 11 (2000), 570-571.

[53] Lydia Plowman, Joanna McPake, and Christine Stephen. 2010. The technologisation of childhood? Young children and technology in the home. Children \& Society 24, 1 (2010), 63-74.

[54] Lydia Plowman, Olivia Stevenson, Christine Stephen, and Joanna McPake. 2012. Preschool children's learning with technology at home. Computers \& Education 59, 1 (2012), 30-37.

[55] Victoria Rideout. 2017. The Common Sense census: Media use by kids age zero to eight. San Francisco, CA: Common Sense Media (2017), 263-283.

[56] Angharad Rudkin. [n.d.]. Digital Childhood. ([n. d.]).

[57] Diane J Schiano and Christine Burg. 2017. Parental Controls: Oxymoron and Design Opportunity. In International Conference on Human-Computer Interaction. Springer, 645-652.

[58] Lori Takeuchi. 2011. Families matter: Designing media for a digital age. (2011).

[59] Rupin R Thakkar, Michelle M Garrison, and Dimitri A Christakis. 2006. A systematic review for the effects of television viewing by infants and preschoolers. Pediatrics 118, 5 (2006), 2025-2031.

[60] Eric Turkheimer, Andreana Haley, Mary Waldron, Brian d'Onofrio, and Irving I Gottesman. 2003. Socioeconomic status modifies heritability of IQ in young children. Psychological science 14, 6 (2003), 623-628.

[61] Elizabeth A Vandewater, Victoria J Rideout, Ellen A Wartella, Xuan Huang, June H Lee, and Mi-suk Shim. 2007. Digital childhood: electronic media and technology use among infants, toddlers, and preschoolers. Pediatrics 119, 5 (2007), e1006-e1015.

[62] Yvonne Vezzoli, Sara Kalantari, Natalia Kucirkova, and Asimina Vasalou. 2020. Exploring the Design Space for Parent-Child Reading. In Proceedings of the 2020 CHI Conference on Human Factors in Computing Systems. 1-12.

[63] Jarrod Walczer. 2019. Unboxing Creators' Algorithmic Trust in Kids' YouTube. Journal of Design and Science (2019).

[64] Pamela Wisniewski, Haiyan Jia, Heng Xu, Mary Beth Rosson, and John M Carroll. 2015. " Preventative" vs." Reactive" How Parental Mediation Influences Teens' Social Media Privacy Behaviors. In Proceedings of the 18th ACM Conference on Computer Supported Cooperative Work \& Social Computing. 302-316.

[65] Ying Xu and Mark Warschauer. 2020. " Elinor Is Talking to Me on the Screen!" Integrating Conversational Agents into Children's Television Programming. In Extended Abstracts of the 2020 CHI Conference on Human Factors in Computing Systems. 1-8.

[66] Sarita Yardi and Amy Bruckman. 2012. Income, race, and class: exploring socioeconomic differences in family technology use. In Proceedings of the SIGCHI Conference on Human Factors in Computing Systems. 3041-3050.

[67] Frederick J Zimmerman and Dimitri A Christakis. 2007. Associations between content types of early media exposure and subsequent attentional problems. Pediatrics 120, 5 (2007), 986-992. 